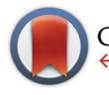

CrossMark \&lick for updates

Cite this: Org. Biomol. Chem., 2016, 14, 11347

Received 28th October 2016, Accepted 16th November 2016

DOI: $10.1039 / c 6 o b 02276 f$

www.rsc.org/obc

\section{Metal-free radical thiolations mediated by very weak bases $\uparrow$}

\author{
Denis Koziakov, Michal Majek and Axel Jacobi von Wangelin*
}

\begin{abstract}
Aromatic thioethers and analogous heavier chalcogenides were prepared by reaction of arene-diazonium salts with disulfides in the presence of the cheap and weak base NaOAc. The mild and practical reaction conditions (equimolar reagents, DMSO, r.t., 8 h) tolerate various functional groups (e.g. $\mathrm{Br}, \mathrm{Cl}, \mathrm{NO}_{2}, \mathrm{CO}_{2} \mathrm{R}, \mathrm{OH}$, $\mathrm{SCF}_{3}$, furans). Mechanistic studies indicate the operation of a radical aromatic substitution mechanism via aryl, acetyloxyl, thiyl, and dimsyl radicals.
\end{abstract}

\section{Introduction}

Sulfur-substituted aromatics constitute a versatile class of building blocks which find numerous applications in the synthesis of bioactive compounds, materials and fine chemicals (Scheme 1). ${ }^{1}$ Besides electrophilic aromatic substitutions with conc. sulfuric acid, various synthetic procedures have been reported for the construction of aryl-S bonds from aryl electrophiles and sulfur nucleophiles. The most prominent methods are transition metal-catalyzed thiolations of aryl halides ${ }^{2}$ and Sandmeyer-type ${ }^{3}$ radical substitutions of arenediazonium salts $^{4}$ (Scheme 2, top). The latter procedure can be performed

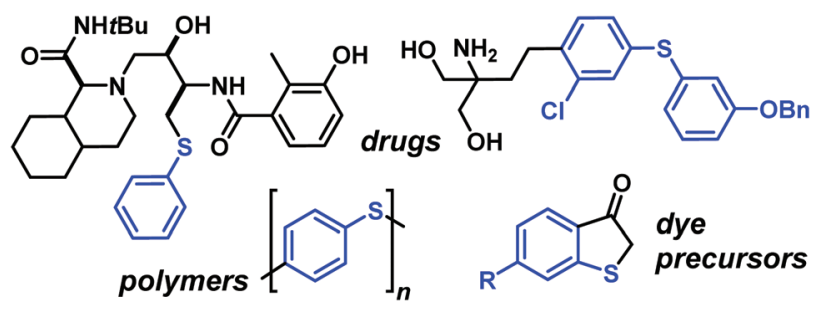

Scheme 1 Selected compounds containing aryl-S entities.

Institute of Organic Chemistry, University of Regensburg, Germany.

E-mail: axel.jacobi@ur.de; Fax: +49 (o)941943-4617; Tel: +49 (0)941943-4802

$\dagger$ Electronic supplementary information (ESI) available: Experimental procedures, analytical data of all new compounds. See DOI: 10.1039/c6ob02276f

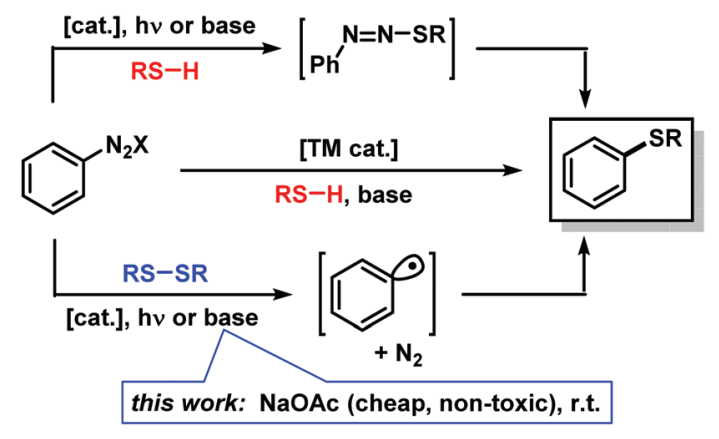

Scheme 2 Thiolation methods of arenediazonium salts.

under metal-free basic conditions but affords only moderate yields and bears significant hazard potential due to the intermediacy of explosive azosulfides. ${ }^{5}$ An elegant alternative is the use of disulfides in radical aromatic substitutions which are initiated by single-electron transfer (SET) and operate under mild conditions. ${ }^{6}$ Base-free aromatic thiolations with disulfides were recently realized by organic photoredox-catalysis. ${ }^{7}$ However, light-mediated processes require the presence of a suitable photo-sensitizer and irradiation with a powerful light source, operate at low concentrations over long reaction times, and generally suffer from the attenuation of light intensity in solution (Lambert-Beer law).

Powerful metal-free electron donors are mostly strong bases $^{8}$ and nucleophiles which are incompatible with sensitive functional groups and protic solvents. However, even weak bases and nucleophiles can trigger radical aromatic substitutions $\left(S_{R} A r\right)$ at electrophilic aryl-X if the elimination of $X$ was irreversible or a facile bond homolysis can occur. ${ }^{9,10}$ Following observations on mechanistically related photo-redox substitutions, ${ }^{7}$ we directed our attention at SET-mediated reactions of disulfides with arenediazonium salts. ${ }^{11}$ Here, we present an operationally facile protocol which utilizes the cheap, environmentally benign, and weak base sodium acetate (NaOAc) in radical aromatic substitutions of arenediazonium salts with disulfides under mild reaction conditions (Scheme 2, bottom). 


\section{Method development}

Simple inorganic bases are attractive due to their low price, low toxicity, and facile removal from organic products while organic bases are mostly more expensive, environmentally problematic, and less facile to remove from organic phases. We studied the model reaction of 4-nitrobenzenediazonium tetrafluoroborate, containing two $\pi$-electrophilic sites, with dimethyldisulfide (Table 1). Various simple bases were competent in this thiolation protocol. $N, N$-Dimethylhydrazine was most active; ${ }^{12}$ however, we refrained from further studies due to the toxicity and hazard potential as carcinogen, explosive, and groundwater pollutant. ${ }^{13}$ Strong bases (e.g. KOtBu, KHMDS, $n$-BuLi) gave lower selectivities and many byproducts. Polar solvents (acetonitrile, methanol, dimethylsulfoxide (DMSO)) exhibited high reagents solubility and good yields. Identical reactions in $N, N$-dimethylformamide (DMF) underwent competing hydrodediazotation $(25 \%)$; in benzene 4-nitrobiphenyl was formed (15\%). Significantly higher selectivities were observed in the absence of air and moisture. Gratifyingly, no excess of reagents was required. The optimized conditions (equimolar $\mathrm{ArN}_{2} \mathrm{BF}_{4}, \mathrm{NaOAc}, \mathrm{Me}_{2} \mathrm{~S}_{2}, 0.2 \mathrm{M}$ in DMSO, $\left.18{ }^{\circ} \mathrm{C}, 8 \mathrm{~h}\right)$ enabled clean conversion to the arylthioether with minimal formation of anisole as reduction by-product $(<3 \%)$. Similar yields were obtained when using other simple carboxylates (Scheme 3).

Table 1 Selected optimization experiments ${ }^{a}$

\begin{tabular}{|c|c|c|c|c|}
\hline Entry & $\begin{array}{l}\text { Equiv. } \\
\mathrm{Me}_{2} \mathrm{~S}_{2}\end{array}$ & $\begin{array}{l}\text { Base } \\
\text { (equiv.) }\end{array}$ & Conditions & $\begin{array}{l}\text { Yield }^{b} \\
{[\%]}\end{array}$ \\
\hline 1 & 5 & - & & 0 \\
\hline 2 & 1 & $n-\mathrm{Bu}_{4} \mathrm{NI}(1.5)$ & & 66 \\
\hline 3 & 5 & $\mathrm{KO} t \mathrm{Bu}(5)$ & & 65 \\
\hline 4 & 5 & $\mathrm{NaOAc}(5)$ & & 85 \\
\hline 5 & 1.5 & $\mathrm{NaOAc}(5)$ & & 85 \\
\hline 6 & 1.5 & $\mathrm{NaOAc}(1)$ & & 83 \\
\hline 7 & 1.5 & $\mathrm{NaOAc}(0.5)$ & $16 \mathrm{~h}$ & 56 \\
\hline 8 & 1.5 & $\mathrm{NaOAc}(0.2)$ & $16 \mathrm{~h}$ & 29 \\
\hline 9 & 1 & KOAc (1) & DMSO, r.t., $8 \mathrm{~h}$ & 80 \\
\hline 10 & 0.5 & $\mathrm{NaOAc}(1)$ & DMSO, r.t., $8 \mathrm{~h}$ & 42 \\
\hline 11 & 1 & NaOAc (1) & $\mathrm{H}_{2} \mathrm{O} / \mathrm{THF} / \mathrm{AcMec}$ & $66 / 31 / 73$ \\
\hline 12 & 1 & NaOAc (1) & $\mathrm{MeOH} / \mathrm{DMF} / \mathrm{MeCN}^{c}$ & $77 / 62 / 75$ \\
\hline 13 & 1 & NaOAc (1) & DMSO, r.t., 8 h & $85^{d}(90)^{e}(83)^{f}$ \\
\hline
\end{tabular}

${ }^{a}$ Optimized conditions: 4-Nitrobenzenediazonium tetrafluoroborate (0.6 mmol), NaOAc (0.6 mmol) under $\mathrm{N}_{2}$, DMSO (3 mL), r.t., 8 h. ${ }^{b} \mathrm{GC}$ yields $v s$. internal 1-dodecanenitrile. ${ }^{c}$ Individual reactions in one solvent. ${ }^{d} 80 \%$ isolated yield. ${ }^{e}$ After $60 \mathrm{~h}^{f}{ }^{f} 60{ }^{\circ} \mathrm{C}, 1 \mathrm{~h}$.
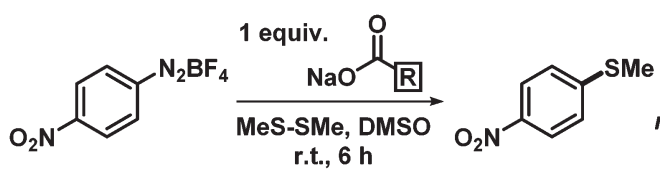

R: $\mathrm{H}: \mathbf{7 8} \%$

Me: $85 \%$ $\mathrm{CF}_{3}: 70 \%$

$-\mathrm{C}_{11} \mathrm{H}_{23}: 69 \%$

Bn: $69 \%$

Ph: $65 \%$
Scheme 3 Similar activity of various sodium carboxylates.
Table 2 NaOAc-mediated methylthiolation of arenediazonium salts ${ }^{a}$

\begin{tabular}{|c|c|c|c|}
\hline $\mathrm{R}$ & $\frac{\text { Mes-SMe }}{\text { DMSO, r }}$ & & $\underbrace{}_{<5 \%}$ \\
\hline $\mathrm{R}^{\prime}$ & Yield [\%] & $\mathrm{R}^{\prime}$ & Yield [\%] \\
\hline 4-OMe & 89 & $3-\mathrm{NO}_{2}$ & 77 \\
\hline 4-Cl & 70 & $2-\mathrm{NO}_{2}$ & 80 \\
\hline $4-\mathrm{NO}_{2}$ & 85 & $2-\mathrm{Br}$ & 69 \\
\hline $4-\mathrm{OH}$ & 87 & 2-SMe & 73 \\
\hline $4-\mathrm{Ph}$ & 58 & $2-\mathrm{CO}_{2} \mathrm{Me}$ & 71 \\
\hline $2,4,6-\mathrm{Cl}_{3}$ & 56 & 1-Naphthyl & 53 \\
\hline
\end{tabular}

${ }^{a}$ Conditions: arenediazonium tetrafluoroborate $(0.6 \mathrm{mmol})$, dimethyl disulfide (0.6 mmol), NaOAc (0.6 mmol), DMSO ( $2 \mathrm{~mL}), 20^{\circ} \mathrm{C}, 8 \mathrm{~h}$.

We then applied the optimized conditions to a series of diversely substituted arenediazonium salts (Table 2). The protocol proved to be rather general with regard to substituents at the arene and the disulfide, respectively. Chloro, bromo, ester, nitro, hydroxy, and naphthyl moities within the diazonium salts were tolerated. Alkyl disulfides afforded slightly higher yields than aryl disulfides (Scheme 4). The trifluoromethylsulfanyl moiety, which attracts great interest from pharmaceutical programs due to their lipophilic properties, could also be introduced by reaction with commercial bis(trifluoromethyl) disulfide in the same (Scheme 4) ${ }^{14}$ Sequential radical 5-exo-dig cyclization and thiolation was observed with 2-(propynyloxy)benzenediazonium tetrafluoroborate to give 3-thioketal benzofurans (Scheme 5) ${ }^{15}$ The attack of the $S$-centered radical on the newly formed double bond is facilitated by the stabilization of the resulting benzyl radical. On the other hand, the corresponding 2-allyloxybenzenediazonium salt

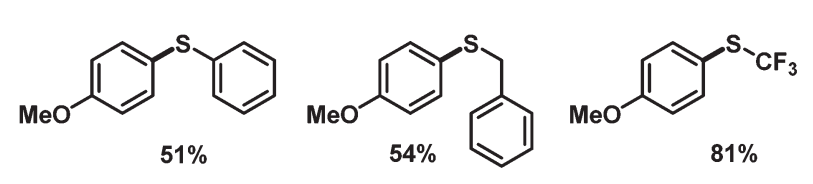

Scheme 4 Preparation of other unsymmetrical aryl thioethers.

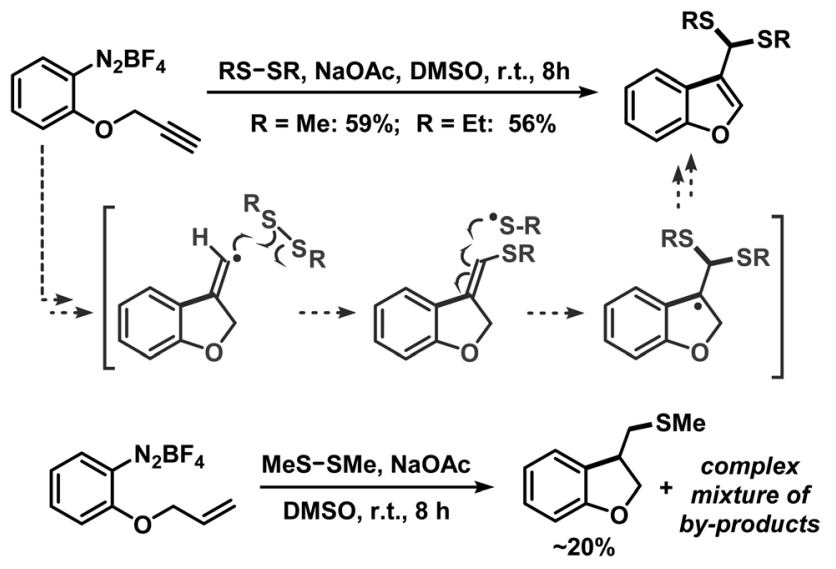

Scheme 5 Base-mediated radical cyclization-thiolation. 


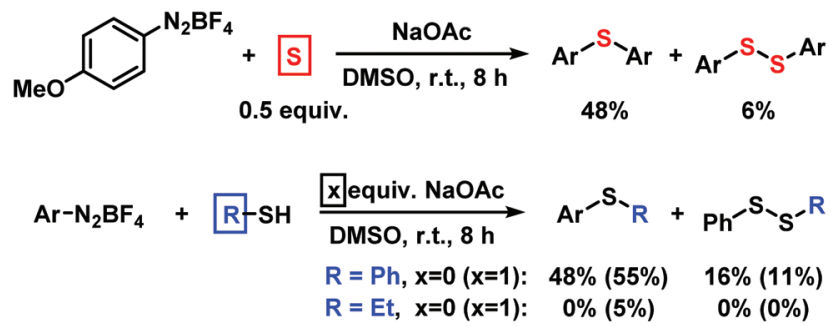

Scheme 6 Procedures with alternative sulfur sources $(\mathrm{Ar}=$ 4- $\mathrm{MeOC}_{6} \mathrm{H}_{4}$ ).

failed to undergo a similarly effective domino reaction but afforded a different thioether skeleton and many by-products (Scheme 5, bottom).

We employed elemental sulfur as alternative thiolation reagents which indeed led to the formation of symmetrical diaryl sulfides in moderate to good yields (Scheme 6, top). While thiols are easy available, they result in the formation of explosive azosulfide intermediates and under our conditions gave only moderate to low yields of the desired thioethers. The direct thiolation with benzenethiol proceeded with moderate yields in the absence of base. With ethanethiol, mostly hydrodediazotation was observed (Scheme 6, bottom).

\section{Mechanistic studies}

Reaction progress analysis documented an immediate onset of reactivity within less than $10 \mathrm{~s}$, more than 50\% conversion within $1 \mathrm{~h}$, and a significantly slower turnover after 1-2 h. This behaviour could be a consequence of two competing reaction mechanisms: a rapid base-induced thiolation and a slow radical chain propagation. ${ }^{16}$ The operation of the latter is also supported by experiments with catalytic amounts of NaOAc (20 mol\% and $50 \mathrm{~mol} \%$ ) which afforded $29 \%$ and $56 \%$ yield, respectively, after $16 \mathrm{~h}$. Further mechanistic insight has already been gained by the initial optimization experiments (see Table 1). The stoichiometry of the reaction (equimolar $\mathrm{ArN}_{2} \mathrm{BF}_{4}, \mathrm{R}_{2} \mathrm{~S}_{2}$, and NaOAc) indicates a loss channel of one half of the disulfide molecule which is not electron transfer in nature $\left(\mathrm{RS}^{\cdot} \rightarrow \mathrm{RS}^{+}+\mathrm{e}^{-}\right)^{16}$ as such a scenario could operate with catalytic amounts of base.

We postulate a mechanism that involves homolysis of the initially formed diazoacetate (Scheme 7). The resultant aryl and acetyloxyl radicals engage in orthogonal onward reactions. The former reacts with the disulfide upon release of a thiyl radical which is trapped by a dimsyl radical derived from $\mathrm{H}$ atom transfer (HAT) with acetyloxyl. The presence of the aryl radical intermediate $\mathrm{Ar}^{\bullet}$ was confirmed by radical trapping with TEMPO (2,2,6,6-tetramethylpiperidin-1-yl)-oxyl in a standard reaction. The aryl radical intermediate attacks the disulfide in an $\mathrm{S}_{\mathrm{H}} 2$ fashion by homolysis of the $\mathrm{S}-\mathrm{S}$ bond in a single step. ${ }^{17}$ The resulting DMSO-SR adducts $(\mathrm{R}=\mathrm{Me}, \mathrm{Ph})$ were detected by ESI-MS (Scheme 7, bottom left). ${ }^{7 a, 18}$ The generation of acetic acid as major byproduct was monitored

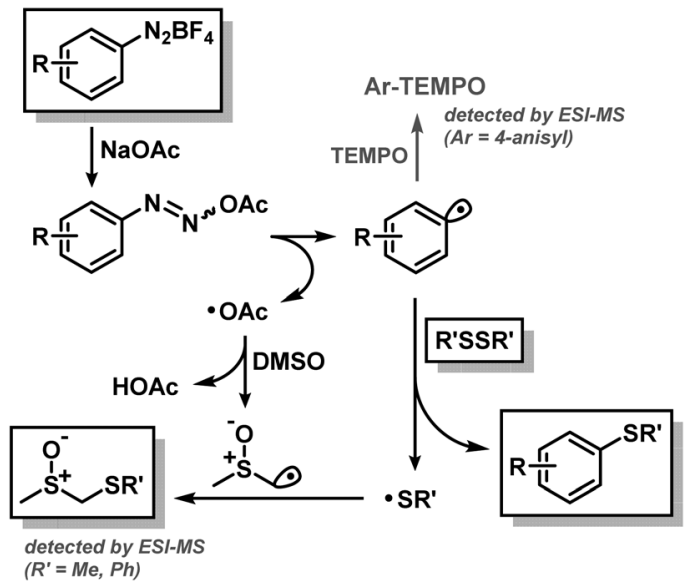

Scheme 7 Postulated weak base-mediated $\mathrm{S}_{\mathrm{R}} \mathrm{Ar}$ mechanism.

indirectly by the continuous decrease of the $\mathrm{pH}$ value over the course of the reaction ( $\mathrm{pH} 8 \rightarrow 4$, after aqueous quench) despite the buffering effect of the weak acid/base pair and the solvent. Crossover-experiments with dimethyl-disulfide and diphenyldisulfide resulted in the formation of the mixed methylphenyl disulfide (MeS-SPh) as byproduct by recombination of free thiyl radicals.

Other mechanistic scenarios could be excluded based on the following instructive experiments and considerations: (i) The operation of the acetate anion as single-electron transfer reagent ${ }^{19}$ is discouraged by the lack of any detectable $\mathrm{CO}_{2}$ formation by head-space MS analyses and gas phase absorptions into aqueous $\mathrm{Ba}(\mathrm{OH})_{2}$. (ii) A direct disulfide-mediated electron transfer was already disproven in entry 1 of Table 1 . Consistently, a solution of arenediazonium salt and NaOAc in DMSO underwent significant hydrodediazotation after $30 \mathrm{~min}$ in the absence of disulfides; deuterium incorporation from DMSO- $d_{6}$ was also observed (Scheme 8, top). (iii) Base-
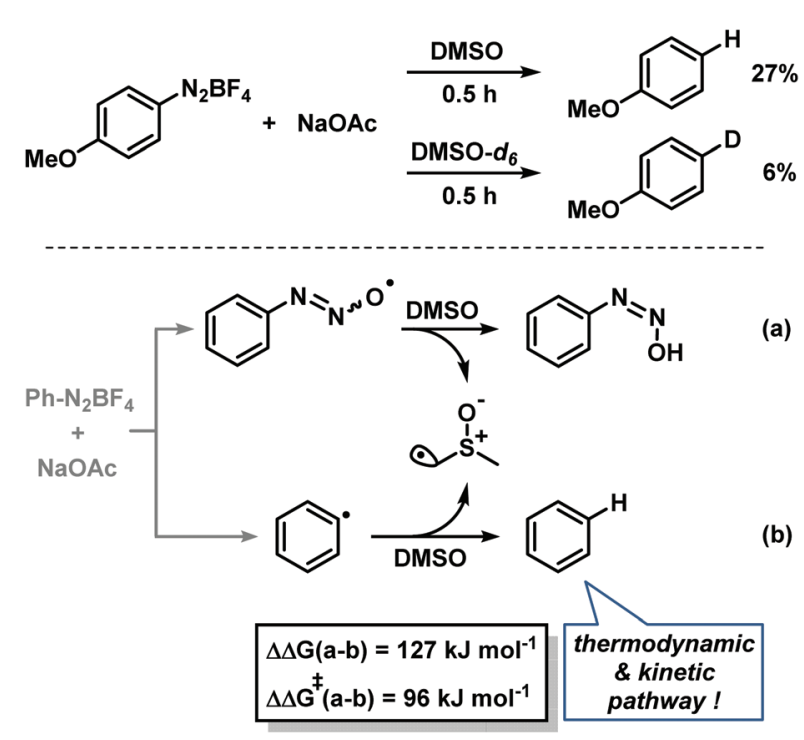

Scheme 8 Experimental and calculated $\mathrm{H}$ atom transfer (HAT). 


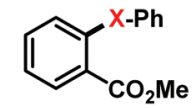

$X=$ Se: $\mathbf{8 2} \%, X=$ Te: $\mathbf{9 7} \%$

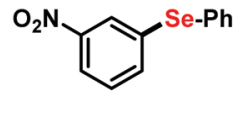

$55 \%$

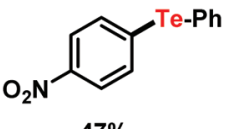

$47 \%$
Scheme 9 Selenations and tellurations under similar conditions.

mediated aryl radical formation from arene-diazonium salts could in principle proceed by SET from the diazotate anion. ${ }^{20}$ On thermodynamic grounds, the diazotate anion/radical appears to be a reasonable 1e-redox couple under weakly basic conditions. ${ }^{21}$ However, this mechanism requires the operation of a highly selective $\mathrm{H}$ atom transfer (HAT) from a suitable $\mathrm{H}$-donor (DMSO) to the azotate radical $^{19}$ but not to the aryl radical intermediate. A DFT-based analysis excludes such mechanism because the HAT to the aryl radical is thermodynamically and kinetically highly favoured (Scheme 8, bottom). ${ }^{20,22}$ (iv) The operation of a dimsyl anion-mediated $\mathrm{S}_{\mathrm{RN}} 1$ mechanism can be excluded by the large $\mathrm{p} K_{\mathrm{a}}$ difference of acetic acid ( 12) and DMSO ( $\sim 35)$ in DMSO. ${ }^{23}$

Under identical conditions, the general protocol was applied to the synthesis of arylselenoethers and aryltelluroethers (Scheme 9). ${ }^{24}$ Employment of the diphenyl dichalcogenides afforded very good yields of the methyl 2-phenylcarboxylate derivatives and moderate yields of nitrobenzene derivatives. Mechanistic studies on related systems were performed by Pandey and coworkers which reported the facile SET oxidation of diselenides in the presence of suitable acceptors and subsequent mesolysis to a phenylselenyl radical and phenylselenyl cation. ${ }^{6 b, 25}$

\section{Conclusion}

We have developed a new metal-free thiolation method for synthesis of arylsulfides which employs the cheap, weak, and environmentally benign base sodium acetate. Experimental and theoretical studies indicated the operation of an initial homolysis of diazoacetates and exclude alternative base-, dimsyl- and diazotate-mediated electron transfer mechanisms. Applications to the synthesis of various functionalized thioethers, selenides, and tellurides demonstrate the scope of this mild base-mediated protocol. Further applications of similar activation mechanisms in radical substitution reactions are currently being investigated.

\section{Experimental section}

\section{General procedure for the synthesis of arenediazonium salts}

The parent aniline $(10 \mathrm{mmol})$ was dissolved in glacial acetic acid $(6 \mathrm{~mL})$ and $32 \%$ aqueous tetrafluoroboric acid $(1.6 \mathrm{~mL})$ at r.t. Then, a solution of $t$-butyl nitrite $(1.2 \mathrm{~mL})$ in glacial acetic acid $(2 \mathrm{~mL}$ ) was slowly added at r.t. over $5 \mathrm{~min}$. Diethylether $(15 \mathrm{~mL})$ was added, and the mixture was cooled to $-30^{\circ} \mathrm{C}$ in order to induce crystallization. The crystals were filtered off, washed with cold diethylether $(2 \times 10 \mathrm{~mL})$ and dried on air to give analytically pure arenediazonium salts.

\section{General procedure for base-induced thiolation, selenylation and telluration}

A vial ( $5 \mathrm{~mL}$ ) was charged with a magnetic stir bar, the arenediazonium salt $(0.5 \mathrm{mmol})$, the disulfide $(0.5 \mathrm{mmol})$ and sodium acetate $(0.5 \mathrm{mmol})$ and capped with a rubber septum. The vial was purged with $\mathrm{N}_{2}$ (5 min). Dry DMSO $(2.5 \mathrm{~mL}$ ) was added. After $8 \mathrm{~h}$ of stirring, water $(5 \mathrm{~mL})$ was added to give an emulsion, which was extracted with diethylether $(3 \times 5 \mathrm{~mL})$. The organic phases were washed with brine $(5 \mathrm{~mL})$ and dried $\left(\mathrm{MgSO}_{4}\right)$. The solvent was evaporated in vacuo; the residue was purified by $\mathrm{SiO}_{2}$ flash column chromatography (pentane/ethyl acetate).

\section{Calculations}

Geometries and energies were calculated using Gaussian G09W. ${ }^{21 a}$ DFT calculations were performed using M06-2X functional, ${ }^{21 b}$ and $6-31+\mathrm{G}(\mathrm{d}, \mathrm{p})$ basis set. Geometry optimizations and single point calculations were done using the polarized continuum model to account for solvation effects.

\section{Acknowledgements}

D. K. thanks the Bayhost program of the State of Bavaria (2014-2015) and the Fonds der Chemischen Industrie (FCI, 2015-2017) for doctoral fellowships. M. M. is a fellow of the Graduate School on "Chemical Photocatalysis" (GRK 1626) of the Deutsche Forschungsgemeinschaft (DFG).

\section{Notes and references}

1 (a) Patai's Chemistry of Functional Groups: The Thiol Group, ed. S. Patai, Wiley-VCH, 1974, vol. 1 and 2; (b) Patai's Chemistry of Functional Groups: The Ether Linkage, ed. S. Patai, Wiley-VCH, 1967, ch. 13; (c) D. N. Jones, in Comprehensive Organic Chemistry, ed. D. H. R. Barton and D. W. Ollis, Pergamon, New York, 1979, vol. 3.

2 (a) I. P. Beletskaya and V. P. Ananikov, Chem. Rev., 2011, 111, 1596; (b) C. C. Eichman and J. P. Stambuli, Molecules, 2011, 16, 590-608; (c) V. Gomez-Benitez, O. BaldovinoPantaleon, C. Herrera-Alvarez, R. A. Toscano and D. Morales-Morales, Tetrahedron Lett., 2006, 47, 5059-5062; (d) O. Baldovino-Pantaleon, S. Hernandez-Ortega and D. Morales-Morales, Inorg. Chem. Commun., 2005, 8, 955959; (e) O. Baldovino-Pantaleon, S. Hernandez-Ortega and D. Morales-Morales, Adv. Synth. Catal., 2006, 348, 236-242; (f) N. Taniguchi, J. Org. Chem., 2004, 69, 6904-6906; (g) S.-I. Fukuzawa, D. Tanihara and S. Kikuchi, Synlett, 2006, 2145-2147; (h) P.-S. Luo, M. Yu, R.-Y. Tang, P. Zhong and J.-H. Li, Tetrahedron Lett., 2009, 50, 1066-1070; (i) W. Fu, T. Liu, Z. Fang, Y. Ma, X. Zheng, W. Wang, X. Ni, M. Hu and T. Tang, Chem. Commun., 2015, 51, 5890-5893; (j) N. Taniguchi and T. Onami, J. Org. Chem., 2004, 69, 
915-920; (k) S. Kumar and L. Engman, J. Org. Chem., 2006, 71, 5400-5403; (l) N. Taniguchi, J. Org. Chem., 2007, 72, 1241-1245.

3 (a) H. H. Hodgson, Chem. Rev., 1947, 40, 251-277; (b) R. Leuckart, J. Prakt. Chem., 1890, 41, 179-224.

4 F. Mo, G. Dong, Y. Zhang and J. Wang, Org. Biomol. Chem., 2013, 11, 1582-1593.

5 (a) J. Laquidara, Chem. Eng. News, 2001, 79, 6; (b) H. Spencer, Chem. Brit., 1977, 13, 240.

6 Selected examples: (a) T. Zincke, Chem. Ber., 1911, 44, 769; (b) A. Luxen and L. Christiaens, Tetrahedron Lett., 1982, 23, 3905; (c) G. Petrillo, R. Novi, G. Garbarino and C. Dellerba, Tetrahedron, 1986, 42, 4007-4016; (d) F. Effenberger and H. Isak, Chem. Ber., 1989, 122, 545; (e) J. A. Burns, J. C. Butler, J. Moran and G. M. Whitesides, J. Org. Chem., 1991, 56, 2648; (f) P. J. Hogg, Trends Biochem. Sci., 2003, 28, 210; $(g)$ M. Erlandsson and M. Hällbrink, Int. J. Pept. Res. Ther., 2005, 11, 261; (h) O. Dmitrenko, C. Thorpe and R. D. Bach, J. Org. Chem., 2007, 72, 8298; (i) D. Witt, Synthesis, 2008, 2491; $(j)$ D. Kundu, S. Ahammed and C. R. Brindabad, Green Chem., 2012, 14, 2024.

7 (a) M. Majek and A. Jacobi von Wangelin, Chem. Commun., 2013, 49, 5507-5509; (b) X. Wang, G. D. Cuny and T. Noël, Angew. Chem., Int. Ed., 2013, 52, 7860-7864.

8 J. P. Barham, G. Coulthard, K. J. Emery, E. Doni, F. Cumine, G. Nocera, M. P. John, L. E. A. Berlouis, T. McGuire, T. Tuttle and J. A. Murphy, J. Am. Chem. Soc., 2016, 138, 7402-7410.

9 (a) L. C. Schmidt, V. Rey and A. B. Penenory, Eur. J. Org. Chem., 2006, 2210-2214; (b) M. E. Buden, J. F. Guastavino and R. A. Rossi, Org. Lett., 2013, 15, 1174-1177; (c) A. Dewanji, S. Murarka, D. P. Curran and A. Studer, Org. Lett., 2013, 15, 6102-6105. For applications of NaOAc in radical substitution reactions, see: $(d)$ U. M. V. Basavanag, A. Dos Santos, L. El Kaim, R. Gamez-Montano and L. Grimaud, Angew. Chem., Int. Ed., 2013, 52, 7194-7197; (e) Y. Sawama, R. Nakatani, T. Imanishi, Y. Fujiwara, Y. Monguchi and H. Sajiki, RSC Adv., 2014, 4, 8657-8660; $(f)$ KOAc-mediated Meerwein alkenylation: C. Molinaro, J. Mowat, F. Gosselin, P. D. O'Shea, J.-F. Marcoux, R. Angelaud and I. W. Davies, J. Org. Chem., 2007, 72, 18561858.

10 (a) R. Francke and D. Little, Chem. Soc. Rev., 2014, 43, 2492-2521; (b) A. Studer and D. P. Curran, Angew. Chem., Int. Ed., 2016, 55, 58-102.

11 Base-mediated thiolations: A. Kumar, B. S. Bhakuni, Ch. D. Prasad, S. Kumar and S. Kumar, Tetrahedron, 2013, 69, 5383-5392; N. Mukherjee, T. Chatterjee and B. C. Ranu, J. Org. Chem., 2013, 78, 11110-11114; R.-Y. Tang, P. Zhong and Q.-L. Lin, Synthesis, 2007, 85-91.

12 S. Shaaban, A. Jolit, D. Petkova and N. Maulide, Chem. Commun., 2015, 51, 13902-13905.

13 K. G. Back and A. A. Thomas, Am. Ind. Hyg. Assoc. J., 1963, 24, 23-27.

14 G. Landelle, A. Panossian and F. R. Leroux, Curr. Top. Med. Chem., 2014, 14, 941-951.
15 (a) A. L. J. Beckwith, C. J. Easton and A. K. Serelis, J. Chem. Soc., Chem. Commun., 1980, 482; (b) A. L. J. Beckwith, Tetrahedron, 1981, 37, 3073; (c) A. L. J. Beckwith and C. H. Schiesser, Tetrahedron, 1985, 41, 3925; (d) J. E. Baldwin, J. Chem. Soc., Chem. Commun., 1976, 734; (e) A. Srikrishna, J. Chem. Soc., Chem. Commun., 1987, 587.

16 (a) F. Dénès, M. Pichowicz, G. Povie and P. Renaud, Chem. Rev., 2014, 114, 2587-2693; (b) M. P. Bertrand and C. Ferreri, in Radicals in Organic Synthesis, ed. P. Renaud and M. P. Sibi, Wiley-VCH, Weinheim, 2001, pp. 485-504.

17 E. H. Krenske, W. A. Pryor and K. N. Houk, J. Org. Chem., 2009, 74, 5356-5360.

18 ESI-MS spectra also documented the formation of TEMPO- $\mathrm{CH}_{3}$ and TEMPO- $\mathrm{CD}_{3}$ adducts from standard reactions performed in DMSO and DMSO- $\mathrm{d}_{6}$, respectively.

19 Electron affinity of the acetyloxy radical: X.-B. Wang, H.-K. Woo, L.-S. Wang, B. Minofar and P. Jungwirth, J. Phys. Chem. A, 2006, 110, 5047-5050.

20 (a) A comprehensive review of radical reactions with arenediazonium salts: C. Galli, Chem. Rev., 1988, 88, 765-792. Diazotate radicals in the presence of weak carboxylate bases: (b) R. Huisgen and G. Horeld, Ann. Chem., 1949, 562, 137; (c) R. Huisgen and H. Nakaten, Ann. Chem., 1951, 573, 181; (d) G. H. Williams, Homolytic Aromatic Substitution, Pergamon, London, 1960; (e) T. Kauffmann, H. O. Friestad and H. Henkler, Ann. Chem., 1960, 634, 64; (f) C. Rüchardt and E. Merz, Tetrahedron Lett., 1964, 5, 2431; (g) C. Rüchardt, B. Freudenberg and E. Merz, Spec. Publ. Chem. Soc., 1965, 154; (h) J. Besse and H. Zollinger, Helv. Chim. Acta, 1981, 64, 529; (i) R. M. Elofson, N. Cyr and J. K. Laidler, Tetrahedron Lett., 1990, 31, 7205; (j) S. Kindt, K. Wicht and M. R. Heinrich, Org. Lett., 2015, 17, 61226125.

21 (a) This mechanism would require the deprotonation of the intermediate arenediazohydroxide by NaOAc which is very unlikely based on the reported $\mathrm{p} K_{\mathrm{a}}$ value of $6-8\left(\mathrm{H}_{2} \mathrm{O}\right)$ : E. S. Lewis and M. P. Hanson, J. Am. Chem. Soc., 1967, 89, 6268-6272; (b) For diazotates in acidic/basic water, see: O. Macháčková and V. Štěrba, Collect. Czech. Chem. Commun., 1972, 37, 3313-3327.

22 (a) M. J. Frisch, G. W. Trucks, H. B. Schlegel, G. E. Scuseria, M. A. Robb, J. R. Cheeseman, G. Scalmani, V. Barone, B. Mennucci, G. A. Petersson, H. Nakatsuji, M. Caricato, X. Li, H. P. Hratchian, A. F. Izmaylov, J. Bloino, G. Zheng, J. L. Sonnenberg, M. Hada, M. Ehara, K. Toyota, R. Fukuda, J. Hasegawa, M. Ishida, T. Nakajima, Y. Honda, O. Kitao, H. Nakai, T. Vreven, J. A. Montgomery, Jr., J. E. Peralta, F. Ogliaro, M. Bearpark, J. J. Heyd, E. Brothers, K. N. Kudin, V. N. Staroverov, R. Kobayashi, J. Normand, K. Raghavachari, A. Rendell, J. C. Burant, S. S. Iyengar, J. Tomasi, M. Cossi, N. Rega, J. M. Millam, M. Klene, J. E. Knox, J. B. Cross, V. Bakken, C. Adamo, J. Jaramillo, R. Gomperts, R. E. Stratmann, O. Yazyev, A. J. Austin, R. Cammi, C. Pomelli, J. W. Ochterski, R. L. Martin, K. Morokuma, V. G. Zakrzewski, G. A. Voth, P. Salvador, J. J. Dannenberg, S. Dapprich, A. D. Daniels, Ö. Farkas, 
J. B. Foresman, J. V. Ortiz, J. Cioslowski and D. J. Fox, Gaussian 09, Rev. E.01, Gaussian Inc., Wallingford CT, 2009; (b) Y. Zhao and D. G. Truhlar, Theor. Chem. Acc., 2008, 120, 215-251.

23 (a) J. F. Bunnett, Acc. Chem. Res., 1978, 11, 413-420; (b) C. L. Øpstad, T.-B. Melø, H.-R. Sliwka and V. Partali, Tetrahedron, 2009, 65, 7616-7619; (c) K. L. Handoo and A. Kaul, Indian J. Chem., Sect. B: Org. Chem. Incl. Med. Chem., 1992, 31, 561; (d) R. A. Alonso and R. A. Rossi, Tetrahedron Lett., 1985, 26, 5763-5764; (e) N. Kornblum and A. S. Erickson, J. Org. Chem., 1981, 46, 1037-1039.
24 For selected works on dichalcogenide reactions, see: (a) A. L. Stein, F. N. Bilheri and G. Zeni, Chem. Commun., 2015, 51, 15522; (b) G. Sartori, J. S. S. Neto, A. P. Pesarico, D. F. Back, C. W. Nogueiraa and G. Zeni, Org. Biomol. Chem., 2013, 11, 1199; (c) A. R. Rosario, K. K. Casola, C. E. S. Oliveira and G. Zeni, Adv. Synth. Catal., 2013, 355, 2960-2966.

25 (a) G. Pandey, K. S. Sesha Poleswara Rao, D. K. Palit and J. P. Mittal, J. Org. Chem., 1996, 61, 6799-6804; (b) G. Pandey and S. R. Gadre, Acc. Chem. Res., 2004, 37, 201-210. 